Article

\title{
Quality Assessment of the Bidirectional Reflectance Distribution Function for NIR Imagery Sequences from UAV
}

\author{
Damian Wierzbicki * (1), Michal Kedzierski, Anna Fryskowska and Janusz Jasinski \\ Institute of Geodesy, Faculty of Civil Engineering and Geodesy, Military University of Technology, \\ Warsaw 00-908, Poland; michal.kedzierski@wat.edu.pl (M.K.); anna.fryskowska@wat.edu.pl (A.F.); \\ janusz.jasinski@wat.edu.pl (J.J.) \\ * Correspondence: damian.wierzbicki@wat.edu.pl; Tel.: +48-261-83-92-91
}

Received: 30 July 2018; Accepted: 21 August 2018; Published: 24 August 2018

\begin{abstract}
Imaging from low altitudes is nowadays commonly used in remote sensing and photogrammetry. More and more often, in addition to acquiring images in the visible range, images in other spectral ranges, e.g., near infrared (NIR), are also recorded. During low-altitude photogrammetric studies, small-format images of large coverage along and across the flight route are acquired that provide information about the imaged objects. The novelty presented in this research is the use of the modified method of the dark-object subtraction technique correction with a modified Walthall's model for correction of images obtained from a low altitude. The basic versions of these models have often been used to radiometric correction of satellite imagery and classic aerial images. However, with the increasing popularity of imaging from low altitude (in particular in the NIR range), it has also become necessary to perform radiometric correction for this type of images. The radiometric correction of images acquired from low altitudes is important from the point of view of eliminating disturbances which might reduce the capabilities of image interpretation. The radiometric correction of images acquired from low altitudes should take into account the influence of the atmosphere but also the geometry of illumination, which is described by the bidirectional reflectance distribution function (BRDF). This paper presents a method of radiometric correction for unmanned aerial vehicle (UAV) NIR images. The study presents a method of low-altitude image acquisition and a fusion of the method of the dark-object subtraction technique correction with a modified Walthall's model. The proposed solution performs the radiometric correction of images acquired in the NIR range with the root mean square error (RMSE) value not exceeding $10 \%$ with respect to the original images. The obtained results confirm that the proposed method will provide effective compensation of radiometric disturbances in UAV images.
\end{abstract}

Keywords: photogrammetry; unmanned aerial vehicle; radiometric correction; bidirectional reflectance distribution function; quality assessment

\section{Introduction}

The determination of the radiometric quality of images acquired from low altitudes using the bidirectional reflectance distribution function (BRDF) is now a challenge in remote sensing and digital-image processing. Contemporary in situ measurements of the BRDF are costly and ineffective. So far, radiometric corrections were performed mainly on satellite-imagery data and classical aerial images. It is one of the most important issues in modern photogrammetry and remote sensing, especially in its many practical applications related to the natural environment. Many studies are often based on imagery data from different periods of time. Due to the impact of time and possible 
differences in seasons during which imagery was acquired, the objects within the scene may differ greatly in terms of pixel brightness. So far, many models of radiometric correction have been developed, but are applicable only to satellite imagery. In addition, these models are very complex and allow only to achieve approximate results. Therefore, it is necessary to carry out research on the suitability of modified models of radiometric correction, which until now were used to correct satellite imagery and classic aerial images, to correct images obtained from a low altitude. The main difference between satellite and aerial images, and low altitude images is the quality of the imaging sensor used and the imaging altitude. The application of UAVs for the acquisition of low-altitude images for remote sensing is already common. However, the radiometric quality of images acquired from low altitudes or the impact of the BRDF on UAV image-brightness distribution has not been considered in a broader sense, until now. So far, it has been mentioned in References [1,2]. Moreover, the radiometric and geometric calibration of cameras installed on UAVs often requires accurate information about the BRDF of ground reference targets, which may be natural or artificial [3,4]. In a different approach, the methods of radiometric correction of images may be grouped into empirical or semiempirical corrections. The methods provide a relative correction between images based on the DN (pixel value of image) information of the images. The empirical corrections are based on a statistical approach using mainly equalizing histograms. The other group of semiempirical corrections takes into account the most important radiometric effects like the BRDF or models of the atmosphere [5].

So far, the application of general models for correcting the brightness of objects in the entire image simultaneously, often resulted in unwanted changes of brightness of small objects in the image [6,7]. Usually, compact digital cameras that acquire images in the RGB and NIR ranges are installed on board low-cost UAVs. They are usually equipped with a constant focal length lens of a conical field of view that results in variable angle of observation in the image plane [8]. Usually, a classical photogrammetric block of images acquired from low altitudes has both a longitudinal and latitudinal overlay of $75 \%$. It may cause some objects to be imaged in even several images. The same object imaged in the specific images will have various values of brightness, especially in the NIR-range images. Moreover, in such images the distribution of the BRDF will, to a large extent, depend on atmospheric conditions, like cloud cover, haze, or mist, and the angle of incident solar radiance. The radiometric correction of images acquired from low altitudes should be a basic process before the application of proper remote-sensing processing, especially in cases when the task is to acquire such data, e.g., the reflectance coefficients necessary for the radiometric correction of images. So far, the radiometric and geometric calibration of the sensor in laboratory conditions was one of the most important phases of the procedure. Nowadays, more and more research is conducted in order to apply methods of self-calibration or calibration in situ with the simultaneous acquisition of imagery data and orienting the images, DTM/DSM processing, radiometric correction of images, and final products in the form of orthophoto mosaic [1].

Research concerning the determination of the BRDF for images used in remote sensing has already been conducted for several years. The researchers observed in their experiments [9-12] that the BRDF model of an object might be determined with reasonable accuracy using only viewing zenith and viewing azimuth angles as inputs.

It is thus important to develop a model of radiometric correction of images acquired from low altitudes that will take into account the impact of the so-called low atmosphere and the angle of incidence of solar radiation during the acquisition of the imagery data. The conducted research proposes an approach that takes into account the impact of the haze effect and the geometry of illumination described by the BRDF.

\section{Characteristic Radiometric Correction with the BRDF Function}

When considering a beam of light incident on a surface and its intensity, it may be stated that it depends on the properties of the surface, the location, and type of the light source as well as the conditions of observation. In case of anisotropic surfaces, a change of any of these parameters results 
in a change of the surface luminance $[13,14]$. The characteristics of the light reflection for a specific surface are described by BDRF defined by Nicodemus [15]. The function may be defined for a specific wavelength as the ratio of radiance dLs of the light reflected from a surface element ds in the direction to the irradiance dEi of the surface element from the direction, as in the figure below (Figure 1) [16]:

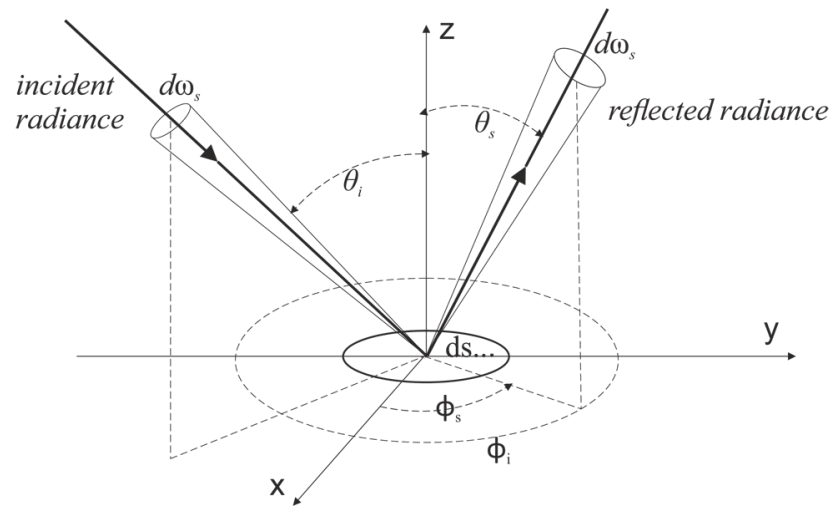

Figure 1. Geometry of the light beams as in the bidirectional reflectance distribution function (BRDF) definition [16].

In practice, the intensity Ps is determined of the reflected light from a discrete detector in the direction of the surface element $S$ encompassing radiation from a solid angle $\Omega$. Then, the BRDF may be determined using the following approximation [16]:

$$
\begin{aligned}
& \operatorname{BRDF}\left(\theta_{i}, \phi_{i}, \theta_{s}, \phi_{s}\right)=\frac{d L_{s}}{d E_{i}} \approx \frac{\frac{P_{s}\left(\theta_{i}, \phi_{i}, \theta_{s}, \phi_{s}\right)}{\Omega S \cos \theta_{s}}}{\left(\frac{P_{i}}{S}\right)}= \\
& =\frac{P_{S}\left(\theta_{i}, \phi_{i}, \theta_{s}, \phi_{s}\right)}{P_{i} \Omega \cos \theta_{s}}\left[s r^{-1}\right]
\end{aligned}
$$

where:

$P_{i}$-the power of the radiation incident on the studied surface area.

In photogrammetry and remote sensing, the BRDF describes the function of incidence and reflection of the light from a terrain surface by means of a physical model. Moreover, the BRDF plays an important role in the radiometric correction of satellite images. In the case of classic aerial images and images acquired from low altitudes, corrections using this function are still being studied. However, new methods based on the radiometric correction of UAV images have recently been proposed [1,17]. Low-altitude imaging is more and more often done in various weather and lighting conditions. Therefore, radiometric correction requires the development of new methods. In their work they proposed that, for low-altitude images, the central radiation elements incident into the camera sensor are the surface of reflected sunlight $\left(L^{s u}(\lambda)\right)$ and surface diffuse radiance $\left(L^{s u}(\lambda)\right)$ [17-19]:

$$
\begin{aligned}
& L_{\text {at_sensor }}(\lambda)=L^{s u}(\lambda)+L^{s d}(\lambda)= \\
& =\rho\left(\lambda, \theta_{i}, \varphi_{i}, \theta_{r}, \varphi_{r}\right) \tau_{v}(\lambda) \tau_{s}(\lambda) E^{0}(\lambda) \\
& \cos (\theta(x, y)) / \pi+F(x, y) \rho\left(\lambda, 2 \pi, \theta_{r}, \varphi_{r}\right) . \\
& \cdot \tau v(\lambda) E^{d}(\lambda) / \pi
\end{aligned}
$$

where $\rho\left(\lambda, \theta_{i}, \varphi_{i}, \theta_{r}, \varphi_{r}\right)$ is the BRDF and $\rho\left(\lambda, 2 \pi, \theta_{r}, \varphi_{r}\right)$ is the reflectance distribution function for diffuse light, $\tau_{v}(\lambda)$ and $\tau_{s}(\lambda)$ are the atmospheric transmittance in the view and solar paths, respectively, $E^{0}(\lambda)$ is the spectral irradiance on top of the atmosphere, $E^{d}(\lambda)$ is the spectral irradiance on the surface due to diffuse illumination, and $\theta$ is the solar incidence angle on a surface. $\theta_{i}$ and $\theta_{r}$ are the illumination and reflected light zenith angles, and $\varphi_{i}$ and $\varphi_{r}$ are the azimuth angles, respectively [17]. Another aspect 
of research concerning radiometric correction is the phenomenon that, for UAV images, very often the main source of heterogeneousness is the effect of a "hot spot"-part of the image that seems to be brighter when the direction of image observation gets close to the direction of sunlight $[1,20]$. This effect may be corrected using the BRDF model with the assumption that at the same time the ground reflectance and atmospheric effects coefficients are anisotropic. Very often, in the case of low-altitude images the reflection of sunlight from the imaged objects is non-Lambertian and it enhances the "hot-spot" effect. The BRDF models may be grouped in two sets of types: physical and empirical. In the case of low-altitude images, the empirical model is more practical since the model parameters may be calculated for it.

\subsection{Empirical Models of Radiometric Correction}

In the case of a lack of data from external measurements, the impact of the atmosphere on the quality of low-altitude images may be determined by means of statistical methods based on the DN value for each channel of the image. The empirical models include [21]:

Simple Dark Pixel Subtraction:-the model takes into account the shift of histograms in the specific channels depending on the angle of image acquisition [22]. It is caused by reflected light from outside the field of view of the sensor, which reaches the field of view of the sensor even if the ground reflection coefficient is equal to zero.

Modified Chavez Method: In some cases when the image content was not homogeneous but it contained urban areas, forests or flat areas, excessive correction was observed in the RED and NIR channels [23]. In such cases, the $\lambda-k$ rule was proposed for the atmospherically scattered radiance. The value of the $\kappa$ coefficient was in the range from 0.5 for haze in the atmosphere to 4.0 for a clear Rayleigh-type atmosphere. Due to the fact that the blue band shift represents the greatest impact of the atmosphere, it may be expected that the values determined for the channel will be the most accurate ones. The determined value of the shift (calibrated) enables the determination of the value of $\kappa$. The greater the shift in the DN values of the pixels, the thicker the haze of the atmosphere. Moreover, the $\mathrm{k}$-coefficient rule depends on the altitude of flight. In the case of images acquired from low altitudes, the useful range of altitudes will usually be within 100 to $300 \mathrm{~m}$. The values of the shift for other channels including NIR are presented in Reference [24].

Modified Walthall Method: Numerous physical and empirical models of the BRDF have been developed in a few dozen years. However, for the purpose of the study of low-altitude images, it is sufficient to apply modified empirical models. A model developed using the Walthall method [25] is one of such models. Walthall proposed in his solution a linear semiempirical model that took into account the view zenith and the relative azimuth. Additionally, the model was improved by Nilson and Kuusk, who took into account the solar-zenith dependence $[20,26,27]$. The model may be applied to each channel separately. The correction may be calculated for all pixels:

$$
\rho\left(\theta_{i}, \theta_{\mathrm{r}}, \varphi\right)=a \theta_{i}^{2} \theta_{r}^{2}+b\left(\theta_{i}^{2}+\theta_{r}^{2}\right)+c \theta_{i}+\theta_{r} \cos \varphi+d
$$

where:

$$
\begin{aligned}
& \rho \text {-modeled reflectance } \\
& \theta_{i} \text {-incident illumination zenith angle } \\
& \theta_{r} \text {-reflection view zenith angle } \\
& \varphi \text {-relative azimuth angle } \\
& a, b, c, d \text {-free parameters }
\end{aligned}
$$

\subsection{Proposed Methodology of Radiometric Correction of UAV NIR Images}

Having in mind the above described premises, the application of dark-object subtraction technique (DOS) was proposed for the first phase of image correction. The process consists in subtracting a defined value of DN of reflection from dark objects. The method assumes a simplified model of 
radiation scattering in the atmosphere. For images acquired from UAVs, it is assumed that there is no scattered radiation reflected from the object. The reflection depends only on the radiation directly reflected from the object and radiation scattered in the atmosphere that was not reflected from the Earth's surface (Figure 2). In the next phase, a modified version of Walthall's empirical model of the BRDF is proposed as a model adjusted to the needs of the correction of images from UAVs. It is assumed that in the case of low-altitude images, the flight time is usually up to 40 minutes; therefore, the illumination direction may be assumed as constant for the entire block. The adapted Walthall model for radiometric correction then has the form:

$$
\rho\left(\theta_{i}, \theta_{r}, \varphi\right)=b \theta_{r}^{2}+c \theta_{r} \cos \varphi+d
$$

In this case, the recent value of the constant $d$ determined empirically is dependent on the channel for which it is applied.

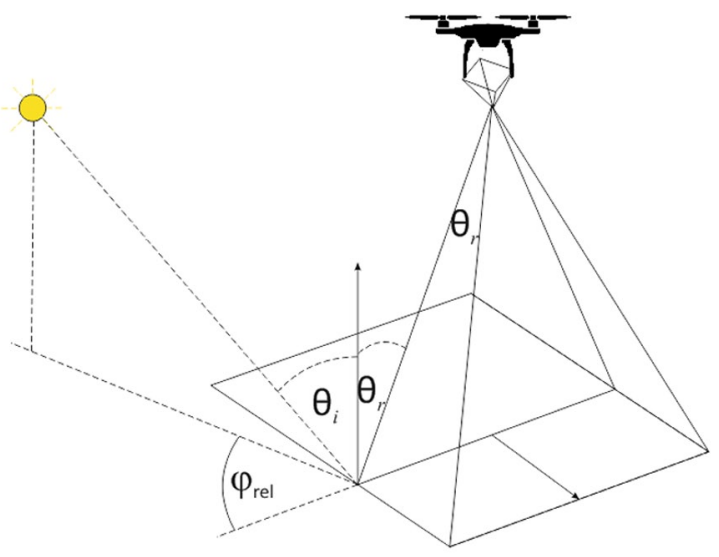

Figure 2. View and relative azimuth angle for UAV images (based on Reference [20]).

The proposed method of radiometric correction of images is applied independently for each channel using the empirically determined model components.

\section{Materials and Methods}

\subsection{Test Area}

The test area was located in the vicinity of Tylicz $\left(49^{\circ} 23^{\prime} 45^{\prime \prime}, 21^{\circ} 01^{\prime} 25^{\prime \prime}\right)$ (Poland) (Figure 3 ) at elevations of over $600 \mathrm{~m}$ above mean sea level indicating mountainous terrain.

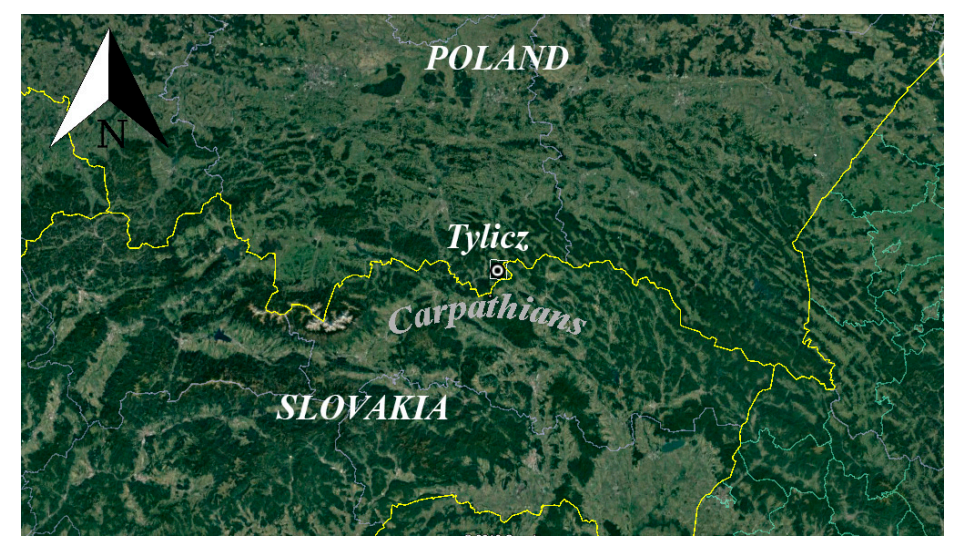

Figure 3. Location of the study area. 
The area's altitude is much more differentiated (there are greater altitude differences) as compared with the quarry. The acquired images covered a fragment of a hill including a part of a ski lift (southern part) and an area of a town with dense settlement (northern part). The northern and southern parts are separated by the Muszynka river flowing across Tylicz. Along the river bed on the southern side there are forests. The area of the hill at the time of flight was covered with low grass, while the area with the ski slope was covered with snow. The northern part of the study area is urbanized to a low degree. There are detached houses, roads and technical infrastructure, single trees, bushes, and mainly grass. The photogrammetric flights were done in March 2016 and February 2017.

\subsection{Data Acquisition}

The NIR imagery data were acquired by means of the Trimble UX5 platform. It is an unmanned aerial vehicle adapted for the acquisition of imagery data of high-terrain resolution. It is made mainly of light EPP foam and it is equipped with electric propulsion. UX5 is a fixed-wing UAV. It is capable of entirely autonomous flying at an indicated altitude with indicated longitudinal and latitudinal coverage of the images due to its onboard Global Positioning System/Inertial Navigation System (GPS/INS) system. The flight route may be monitored by means of the flight controller in real time. The UX5 platform enables automatic triggering of the camera shutter to acquire images of the Earth's surface. The aerial vehicle starts from a special mechanical launcher. The system may operate in wind up to $18 \mathrm{~m} / \mathrm{s}$ and weather conditions not more severe than light rain. Sony NEX-5T (Sony, Tokyo, Japan) was mounted on board the Trimble UX5 for the acquisition of imagery data. It is a compact digital camera equipped with a complementary metal-oxide-semiconductor (CMOS) matrix of 16.1 megapixels (maximum image resolution of $4912 \times 3264$ pixels). The images were recorded in the JPEG format with dissipative data compression. The camera was equipped with Voigtlander lenses of a constant focal length of $15 \mathrm{~mm}$ and a maximum value of aperture of $\mathrm{f} / 4.5$. The NEX-5T camera was modified to acquire images in its full range of matrix sensitivity. The filter for cutting off radiation of wavelengths higher than $690 \mathrm{~nm}$, originally installed in front of the camera matrix, was removed. The maximum wavelength recorded by the sensor is now about $1050 \mathrm{~nm}$. Photogrammetric flights were conducted in the same test area in a year's interval in various weather and lighting conditions at altitudes of $150 \mathrm{~m}$ and $300 \mathrm{~m}$. The images were acquired with the NIR-enabled camera with a black IR-only longpass filter (B + W 092 Tiffen/Wratten \#89B, the Tiffen Company, Hauppauge, New York, NY, USA), which cut on at $695 \mathrm{~nm}$. The application of the filter caused the imagery to contain NIR only, where the blue pixels (band 3) were again used to record nothing but pure NIR (roughly $800 \mathrm{~nm}-1050 \mathrm{~nm}$ ), while the red band (band 1) in the imagery obtained with this filter was in fact the red edge, roughly from $690 \mathrm{~nm}$ through $770 \mathrm{~nm}$ (Figure 4). All acquired images were recorded with radiometric resolution of 8 bits/channel [28-30].

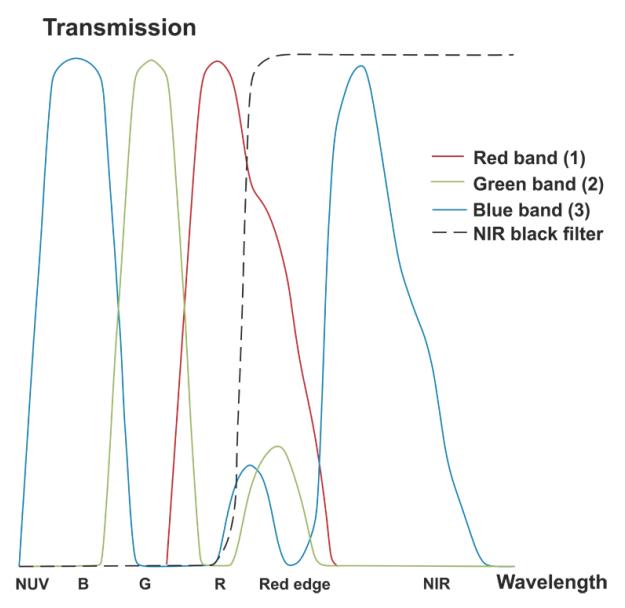

Figure 4. Sony NEX5T spectral response functions [31]. 
During the measurement campaign in March 2016, 264 images were acquired from the altitude of $150 \mathrm{~m}$ at GSD $=0.05 \mathrm{~m}$, while during the measurement campaign in February 2017, 108 images were acquired from the altitude of $300 \mathrm{~m}$ at GSD $=0.1 \mathrm{~m}$. UAS Master software was used to process uncorrected orthophotomosaics and DSM without radiometric corrections. The imagery data were acquired at various altitudes for the verification of the assumptions related to the study of universality of the proposed solution with respect to lighting and altitude of imaging. The designed flight altitudes were related with the commonly used altitudes for low-altitude data acquisition for photogrammetric and remote-sensing studies that are in the range of $150 \mathrm{~m}$ through $300 \mathrm{~m}$ and even $500 \mathrm{~m}$. The characteristics of the test flights are presented in Tables 1 and 2.

Table 1. Characteristics of the image block-dataset from March 2016.

\begin{tabular}{cc}
\hline Sensor & Sony NEX5T with the Black Filter-Tylicz 2016 150 m \\
\hline Acquisition date & 3 March 2016 \\
Acquisition time & $13: 23-13: 55$ \\
Number of images & 264 \\
Spatial resolution $(\mathrm{m})$ & $0.05 \mathrm{~m}$ \\
DN bit range 8 bit & $8 \mathrm{bit}$ \\
Solar zenith Angle $\left(^{\circ}\right)$ & $60.88-63.85$ \\
Solar azimuth Angle $\left({ }^{\circ}\right)$ & $210.72-219.04$ \\
\hline
\end{tabular}

Table 2. Characteristics of the image block—dataset from February 2017.

\begin{tabular}{cc}
\hline Sensor & Sony NEX5T with the Black Filter-Tylicz $\mathbf{2 0 1 7} \mathbf{3 0 0 ~ \mathbf { ~ }}$ \\
\hline Acquisition date & 27 February 2017 \\
Acquisition time & $14: 38-15: 08$ \\
Number of images & 108 \\
Spatial resolution $(\mathrm{m})$ & $0.10 \mathrm{~m}$ \\
DN bit range 8 bit & $8 \mathrm{bit}$ \\
Solar zenith Angle $\left(^{\circ}\right)$ & $69.79-73.62$ \\
Solar azimuth Angle $\left({ }^{\circ}\right)$ & $228.78-235.47$ \\
\hline
\end{tabular}

The process of the radiometric correction of mosaics took into account developing DSM and orthoimages and then the application of DOS technique to the mosaics. The lowest values of DN for the specific images channels were subtracted at the DOS correction application. The operation was done for each channel separately. In order to determine the value of the dark object in the area of Tylicz, Regions of Interest (ROI) of 300 pixels were defined for both sets of test data. The ROIs were located in the area of the river (northern part of the mosaic) where the average values of DN were determined for the specific channels of the images. For the first data set (Tylicz 2016) for Band 1, the DN values were shifted by 23 digital counts, for Band 2 by 3 digital counts, and for Band 3 by 15 digital counts. For the second data set (Tylicz 2017), for Band 1 the DN values were shifted by 19 digital counts, for Band 2 by 2 digital counts, and for Band 3 by 14 digital counts.

The analysis of the images indicated that the greatest impact of the atmosphere is observed in the short waves range (Band 2). As a result, the image histogram after correction shows relocation where the pixels have nonzero values.

The analysis of the histograms (Figures 5-8) shows that the DOS method has a limitation resulting from the relocation of the histogram independently for each band. Figures 6 and 7 show that the greatest relocation is observed for the RED and NIR channels because the haze effect diminishes for longer wavelength channels. Therefore, it is probable that, in some special cases for the NIR channel, the determined value of the $\mathrm{DN}$ difference may be too big in comparison with the real one, especially in cases when the dark pixels are rare. 


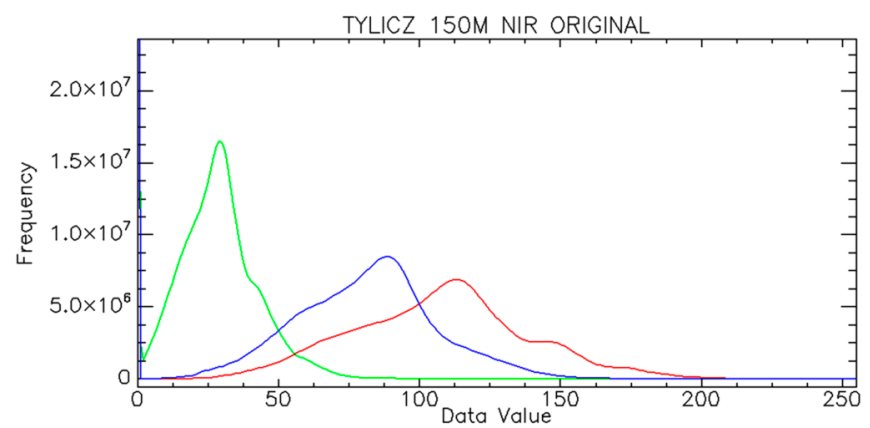

Figure 5. Histogram of uncorrected orthophotomosaic (Tylicz $150 \mathrm{~m}$ NIR). Red line is Band 1, green line is Band 2 and blue line is Band 3.

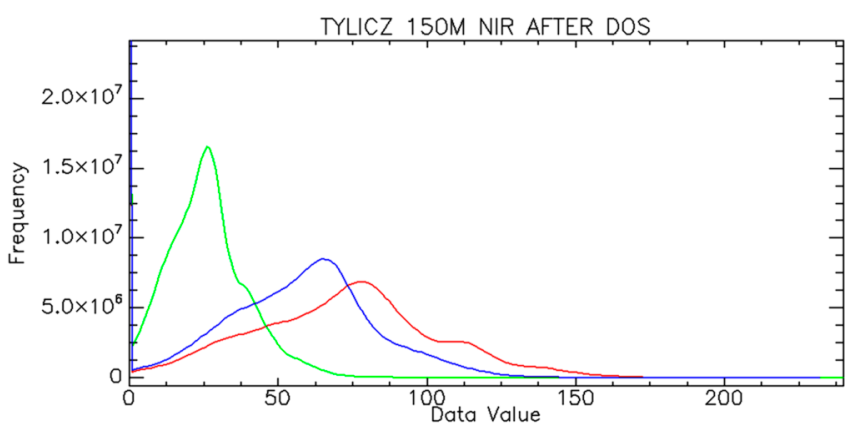

Figure 6. Histogram of corrected orthophotomosaic after dark pixel subtraction. (Tylicz $150 \mathrm{~m}$ NIR). Red line is Band 1, green line is Band 2 and blue line is Band 3.

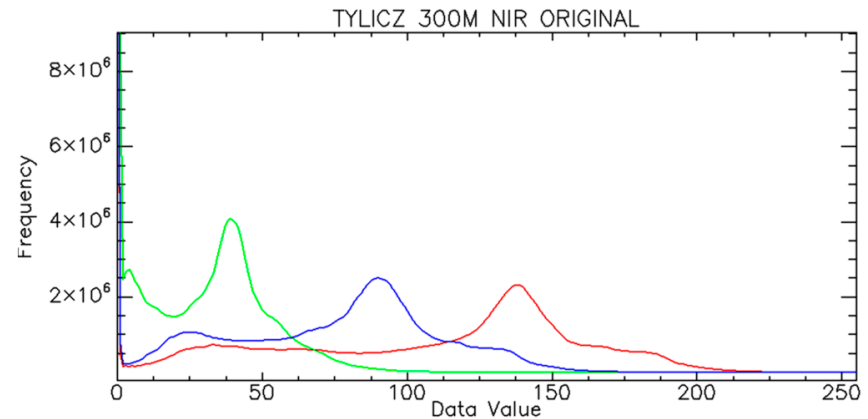

Figure 7. Histogram of uncorrected orthophotomosaic (Tylicz $300 \mathrm{~m}$ NIR). Red line is Band 1, green line is Band 2 and blue line is Band 3.

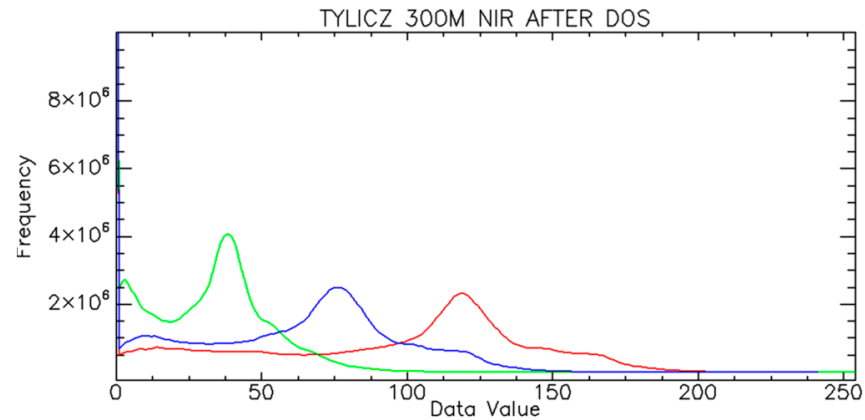

Figure 8. Histogram of corrected orthophotomosaic after dark pixel subtraction (Tylicz $300 \mathrm{~m}$ NIR). Red line is Band 1, green line is Band 2 and blue line is Band 3. 
In the further phase of processing, it is proposed to take into account the BRDF radiometric correction based on the modified Walthall's model. The BRDF model parameters were determined for each channel-Band 1, Band 2, and Band 3-using the initial values of coefficients proposed by Walthall. When determining them, the impact of the zenith view angle, the azimuth angle difference of the sun, and viewing directions, as well as the empirical value of reflectance at nadir view were taken into account for each of the data sets.

Figures 9 and 10 present the results of the radiometric correction of orthophotomosaics. After the application of the radiometric correction, the orthophotomosaics are uniform with respect to radiometry and they take into account the impact of the zenith view angle, the azimuth angle difference of the sun, and viewing directions.

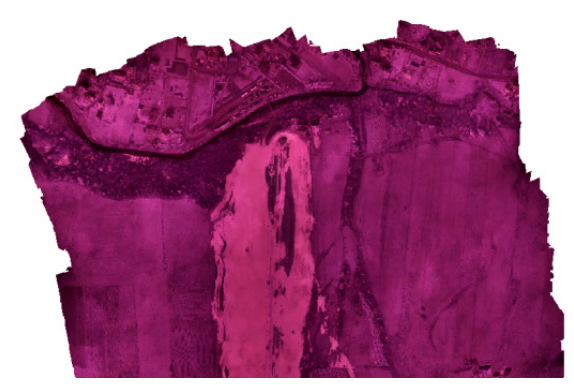

(a)

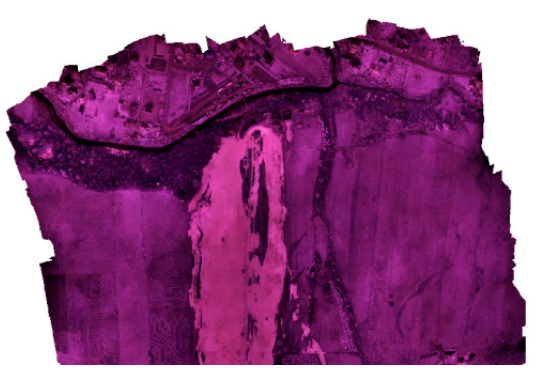

(b)

Figure 9. (a) uncorrected orthophotomosaic, (b) corrected orthophotomosaic after DOS and BRDF correction-dataset-Tylicz 2016.

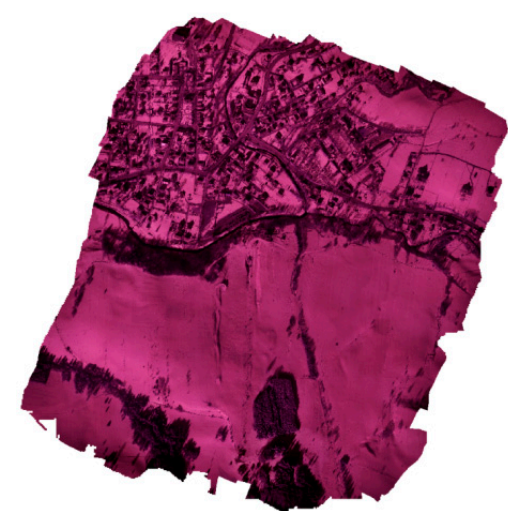

(a)

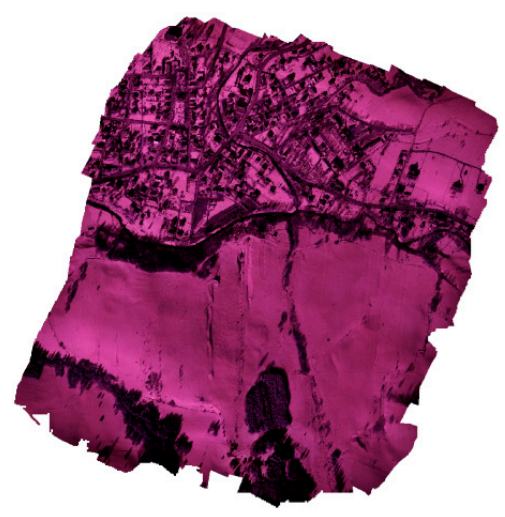

(b)

Figure 10. (a) uncorrected orthophotomosaic, (b) corrected orthophotomosaic after DOS and BRDF correction-dataset-Tylicz 2017.

\section{Results of the Image Quality Assessment}

There are many approaches to image quality assessment presented in publications. There is, however, no universal procedure. Image quality assessment after radiometric correction is often done using the relative values of mean errors (R-RMSE) and correlation coefficient (CC) [32], correlation coefficients, standard deviation values, the differences in pixels brightness between images [33-35]. In the case of digital-images analysis, the relation may be expressed for each channel in the following form:

$$
R-\operatorname{RMSE}_{k}=\sqrt{\frac{\sum_{i=1}^{N}\left(\frac{D N_{\text {fused }(k), i}-D N_{\text {original }(k), i}}{D N_{\text {original }}(k)}\right)^{2}}{N}}
$$


where:

$D N$ - the pixel value

$i$ - the pixel number in band $\mathrm{k}$

$k$-number of the spectral band

$\mathrm{N}$-number of observations

The relative measure of RMSE is applied to avoid large absolute values of deviations for large values of the $\mathrm{DN}$.

The correlation coefficient is determined separately for each channel using the following form:

$$
C C_{\left(I M A G E_{\text {ORIG }}, I M A G E_{C O R R}\right)}=\frac{\operatorname{COV}_{\left(I M A G E_{\text {ORIG }}, I M A G E_{C O R R}\right)}}{S D_{\left(I M A G E_{O R I G}\right)} \cdot S D_{\left(I M A G E_{C O R R}\right)}}
$$

where:

$C_{\left(I M A G E_{O R I G}, I M A G E_{C O R R}\right)}$-the correlation coefficient between original and corrected images

$C O V_{\left(I M A G E_{O R I G}, I M A G E_{C O R R}\right)}$-the covariance between original and corrected images

$S D_{\left(I M A G E_{O R I G}\right)}$-standard deviation of the original image

$S D_{\left(I M A G E_{C O R R}\right)}$-standard deviation of the corrected image

The standard deviation (SD) describes the distribution of data around the mean value of the pixel in the image. Covariance is an un-normalized measure of the relationship between the analyzed data. Normalization is achieved by dividing the covariance by the product of standard deviations of the processed data. This processing results in the correlation coefficient. It is a normalized measure between the original image and the image after applying the DOS and BRDF corrections. The correlation coefficient values are within the range $[-1,1]$. The higher the value of the correlation coefficient is, the more correlated the data are, and, therefore, the higher the similarity between the original image and the corrected one is.

The determined RMSE (Table 3) for both sets of data do not exceed $10 \%$ in all spectral channels. It means that the selected coefficients of the BRDF correction model are reasonable. They do not degrade the content of the image. The smallest value of the error was obtained for Band 2 (Green), which means good maintaining of the spectral information, especially for vegetation. For the NIR channel, the error values were $7.6 \%$ and $9.7 \%$, respectively. The obtained values may indicate degradation of radiometric correction efficiency with increasing UAV flight altitude. It is also related to the changes of the atmospheric model and changing conditions of radiation scattering with altitude.

Table 3. Results of RMSE [\%] for each Band.

\begin{tabular}{cccc}
\hline & Band 1 & Band 2 & Band 3 \\
\hline Tylicz 150 m NIR (March 2016) & 4.9 & 5.1 & 7.6 \\
Tylicz 300 m NIR (February 2017) & 8.7 & 2.9 & 9.7 \\
\hline
\end{tabular}

After the radiometric correction, the correlation values (Table 4) are close to 1 . This means that the global statistics of the image have not changed, while the absolute radiometric quality of the image has improved.

Table 4. Results of the correlation coefficients for each band.

\begin{tabular}{cccc}
\hline & Band 1 & Band 2 & Band 3 \\
\hline Tylicz 150 m NIR (March 2016) & 0.98 & 0.98 & 0.99 \\
Tylicz 300 m NIR (February 2017) & 0.98 & 0.99 & 0.99 \\
\hline
\end{tabular}




\section{Discussion}

A method of radiometric correction of NIR images acquired from low altitudes was proposed as a result of the research. The proposed method is based on a fusion of the dark-object subtraction technique correction and the modified Walthall's BRDF model. The proposed correction method enables the reduction of radiometric differences in the images included in a block due to haze (fog) and the angle of incident solar radiation. The results of the quality assessment of the proposed method are comparable with other research. The determined RMSE do not exceed $10 \%$ in all spectral channels. It means that the selected coefficients of the BRDF correction model are reasonable. In order to prove the efficiency of the developed radiometric correction method, additional comparison analyses were conducted for NIR images acquired from low altitudes for a sample of 898 images obtained within a measurement campaign in October 2017. The images were acquired from $200 \mathrm{~m}$ altitude by means of the UX-5 platform in an area in southeastern Poland. The images were used to produce an orthophotomosaic. A correction according to the proposed method was done for each channel. The obtained values of correlation for channels Band 1 and Band 3 were 0.98 , and for the channel Band 2 0.99. The results confirm that the global statistics of the image have not changed. The values of RMSE (\%) were determined for each channel for additional control. They were $6.3 \%$ (Band 1), $4.2 \%$ (Band 2), and $8.2 \%$ (Band 3). The results of the verification research show that the developed method of radiometric correction of images acquired in the NIR range is also applicable for other imagery data from other regions, other seasons of the year, and other altitudes. The proposed method of radiometric correction of images acquired from low altitudes should always take into account the solar zenith and azimuth angle. Images without any initial corrections, taking into account e.g., the impact of vignetting errors, were used in the conducted research. It is vital information because, often in studies of UAV data, the images are initially corrected by applied software that removes their primitive spectral information. The study of the approach using two different sets of data and a third verification set shows that radiometric correction of NIR images is necessary. As it was proved in the calculated values of correlation, the global statistics of the images have not changed and its absolute radiometric quality has improved. The improvement, even at the level of a few percent, is extremely important because it equalizes the spectral properties of the objects read from the images and it improves the interpretation of the images. Similar results were achieved in the research of Reference [36]. The authors proposed the radiometric correction of hyperspectral images for the assessment of yield quantity and quality of a grass sward. The obtained RMSE value for a corrected nadir mosaic was a bit over $13 \%$ at the correlation coefficient of 0.985 . In other research [37], the authors proposed the application of a modified BRDF correction model for colorized aerial lidar point clouds. In their research, the RMSE value did not exceed $4 \%$ and it was the smallest for the green channel, which is similar to our research. The proposed method of initial radiometric correction of UAV images may be a new introduction to the precise radiometric correction of images with the application of dedicated reflection standards. The presented approach is based on modified models of correction of aerial and satellite images that were adapted for low-altitude images. The research results prove the universality of the presented approach for various altitudes and for various lighting conditions (various seasons). The presented research shows that the application of this type of correction is justified and it indicates the necessity of continuing its improvement for developing correction coefficients, taking into account the impact of the lowest parts of the atmosphere. The conducted experiments also indicate a new research direction for developing new radiometric correction models that would be dedicated exclusively to UAV images.

\section{Conclusions}

The paper presents the results of research concerning the method of radiometric correction and its assessment for NIR images acquired from low altitudes. The authors propose a correction method taking into account the impact of the atmosphere and the direction and angle of incident solar radiation during image acquisition. The image processing is realized in two phases-the first is based on DOS technique correction. The applied method of initial correction based on DOS has, in some cases, 
limitations due to its inaccuracy caused by erroneous determination of zero reflection of dark objects, and due to its inaccuracy in the assessment of DN values in the NIR range, where the impact of atmospheric absorption of radiation increases. An empirical BRDF model was applied in the second phase of correction. Moreover, the proposed method has a lower computational cost when compared to the traditional method of BRDF determination for the radiometric quality of images. The images processed according to the method may be used in remote-sensing applications and developing new haze models.

Future research will focus on developing haze models (especially for radiation haze) and developing radiometric correction for UAV images at altitudes higher than $500 \mathrm{~m}$.

Author Contributions: All authors contributed to the experimental design and participated in the collection of the UAV data. All authors provided editorial advice and participated in the review process. Conceptualization, methodology, and results interpretation by D.W. and M.K. Data analysis by A.F. and J.J.

Funding: This research is supported by the Ministry of National Defense, Republic of Poland, Grant No. GB/ $1 / 2018 / 205 / 2018 / D A-990$

Acknowledgments: This paper has been supported by the Military University of Technology, Faculty of Civil Engineering and Geodesy, Institute of Geodesy, Department of Remote Sensing and Photogrammetry.

Conflicts of Interest: The authors declare no conflict of interest.

\section{References}

1. Honkavaara, E.; Hakala, T.; Markelin, L.; Rosnell, T.; Saari, H.; Mäkynen, J. A process for radiometric correction of UAV image blocks. Photogramm. Fernerkund. Geoinf. 2012, 2, 115-127. [CrossRef]

2. Kedzierski, M.; Wierzbicki, D. Radiometric quality assessment of images acquired by UAV's in various lighting and weather conditions. Measurement 2015, 76, 156-169. [CrossRef]

3. Lucht, W.; Roujean, J.L. Considerations in the parametric modeling of BRDF and albedo from multiangular satellite sensor observations. Remote Sens. Rev. 2000, 18, 343-379. [CrossRef]

4. Markelin, L.; Honkavaara, E.; Peltoniemi, J.; Suomalainen, J.; Ahokas, E. Radiometric evaluation of digital aerial cameras. Int. Arch. Photogramm. Remote Sens. Spat. Inf. Sci. 2006, 36, 6.

5. Chandelier, L.; Martinoty, G. Radiometric aerial triangulation for the equalization of digital aerial images and orthoimages. Photogramm. Eng. Remote Sens. 2009, 75, 193-200. [CrossRef]

6. Krolewicz, S. Impact of the BRDF phenomenon on object brightness within an air photo block. Arch. Fotogram. Kartogr. Teledetekcji 2010, 21, 201-210.

7. Haest, B.; Biesemans, J.; Horsten, W.; Everaerts, J.; Van Camp, N.; Van Valckenborgh, J. Radiometric calibration of digital photogrammetric camera image data. In Proceedings of the ASPRS 2009 Annual Conference, Baltimore, MD, USA, 9-13 March 2009.

8. Grenzdörffer, G.J.; Niemeyer, F. UAV based BRDF-measurements of agricultural surfaces with pfiffikus. Int. Arch. Photogramm. Remote Sens. Spat. Inf. Sci. 2011, 38, 229-234. [CrossRef]

9. Bryant, R.; Qi, J.; Moran, M.S.; Ni, W. Comparison of BRDF models with a fuzzy inference system for correction of bidirectional effects. Remote Sens. Environ. 2003, 88, 221-232. [CrossRef]

10. Cabot, F.; Qi, J.; Moran, M.S.; Dedieu, G. Test of surface bidirectional reflectance models with surface measurements: results and consequences for the use of remotely sensed data. In Proceedings of the Sixth International Symposium on Physical Measurements and Signatures in Remote Sensing, Val d'Isere, France, 17-21 January 1994.

11. Lucht, W.; Lewis, P. Theoretical noise sensitivity of BRDF and albedo retrieval from the EOS-MODIS and MISR sensors with respect to angular sampling. Int. J. Remote. Sens. 2000, 21, 81-98. [CrossRef]

12. Strahler, A.H. Vegetation canopy reflectance modeling-Recent developments and remote sensing perspectives. Remote Sens. Rev. 1997, 15, 179-194. [CrossRef]

13. Yun, S.I.; Kim, K.S. Sky Luminance Measurements Using CCD Camera and Comparisons with Calculation Models for Predicting Indoor Illuminance. Sustainability 2018, 10, 1556. [CrossRef]

14. Yang, G.; Li, C.; Wang, Y.; Yuan, H.; Feng, H.; Xu, B.; Yang, X. The DOM Generation and Precise Radiometric Calibration of a UAV-Mounted Miniature Snapshot Hyperspectral Imager. Remote Sens. 2017, 9, 642. [CrossRef] 
15. Nicodemus, F.E. Reflectance nomenclature and directional reflectance and emissivity. Appl. Opt. 1970, 9, 1474-1475. [CrossRef] [PubMed]

16. Jaglarz, J.; Duraj, R. Geometryczny Pomiar Funkcji BRDF. Available online: https:/ / suw.biblos.pk.edu.pl/ resourceDetailsRPK\&rId $=5990$ (accessed on 22 August 2018).

17. Hakala, T.; Honkavaara, E.; Saari, H.; Mäkynen, J.; Kaivosoja, J.; Pesonen, L.; Pölönen, I. Spectral imaging from UAVs under varying illumination conditions. Int. Arch. Photogramm. Remote Sens. Spat. Inf. Sci. 2013, XL-1/W2, 189-194. [CrossRef]

18. Schowengerdt, R.A. Remote Sensing: Models and Methods for Image Processing, 3rd ed.; Academic Press Inc.: San Diego, CA, USA, 2007; pp. 52-53.

19. Honkavaara, E.; Hakala, T.; Kirjasniemi, J.; Lindfors, A.; Mäkynen, J.; Nurminen, K.; Ruokokoski, P.; Saari, H.; Markelin, L. New light-weight stereosopic spectrometric airborne imaging technology for high-resolution environmental remote sensing case studies in water quality mapping. Int. Arch. Photogramm. Remote Sens. Spat. Inf. Sci. 2013, 1, 139-144. [CrossRef]

20. Beisl, U.; Woodhouse, N. Correction of atmospheric and bidirectional effects in multispectral ADS40 images for mapping purposes. Int. Intl. Arch. Photogramm. Remote Sens. 2004, B7, 1682-1750.

21. Beisl, U.; Telaar, J.; von Schönemark, M. Atmospheric Correction, Reflectance Calibration and BRDF Correction for ADS40 Image Data. In Proceedings of the XXI ISPRS Congress, Commission VII, Beijing, China, 3-11 July 2008.

22. Chavez, P.S. Atmospheric, solar, and M.T.F. corrections for ERTS digital imagery. Proc. Am. Soc Photogramm. 1975, 68, 69.

23. Chavez, P.S., Jr. An Improved Dark-Object Subtraction Technique for Atmospheric Scattering Correction of Multispectral Data. Remote Sens. Environ. 1988, 24, 459-479. [CrossRef]

24. Beisl, U.; Woodhouse, N.; Lu, S. Radiometric processing scheme for multispectral ADS40 data for mapping purposes. In Proceedings of the ASPRS 2006 Annual Conference, Reno, Nevada, 1-5 May 2006; American Society for Photogrammetry and Remote Sensing: Bethesda, MD, USA, 2006; ISBN 1-57083-081-9.

25. Walthall, C.L.; Norman, J.M.; Welles, J.M.; Campbell, G.; Blad, B.L. Simple equation to approximate the bidirectional reflectance from vegetative canopies and bare soil surfaces. Appl. Opt. 1985, 24, 383. [CrossRef] [PubMed]

26. Nilson, T.; Kuusk, A. A reflectance model for the homogeneous plant canopy and its inversion. Remote Sens. Environ. 1989, 27, 157-167. [CrossRef]

27. Honkavaara, E.; Saari, H.; Kaivosoja, J.; Pölönen, I.; Hakala, T.; Litkey, P.; Mäkynen, J.; Pesonen, L. Processing and assessment of spectrometric, stereoscopic imagery collected using a lightweight UAV spectral camera for precision agriculture. Remote Sens. 2013, 5, 5006-5039. [CrossRef]

28. Kedzierski, M.; Fryśkowska, A.; Wierzbicki, D. Opracowania Fotogrametryczne z Niskiego Pułapu; Military University of Technology Press: Warszawa, Poland, 2014; pp. 37-38, ISBN 978-83-7938-047-3. (In Polish)

29. Fryskowska, A.; Kedzierski, M.; Grochala, A.; Braula, A. Calibration of low cost RGB and NIR UAV cameras. Int. Arch. Photogramm. Remote Sens. Spat. Inf. Sci. 2016, 41, 817-821. [CrossRef]

30. Wierzbicki, D.; Fryskowska, A.; Kedzierski, M.; Wojtkowska, M.; Delis, P. Method of radiometric quality assessment of NIR images acquired with a custom sensor mounted on an unmanned aerial vehicle. J. Appl. Remote Sens. 2018, 12, 015008. [CrossRef]

31. Trimble UAS. Trimble UX5 Aerial Imaging Solution Vegetation Monitoring Frequently Asked Questions, Trimble Navigation Limited, KlaasPauly, (2013). Available online: http://surveypartners.trimble.com (accessed on 19 April 2018).

32. Markelin, L.; Honkavaara, E.; Schlaepfer, D.; Bovet, S.T.; Korpela, I. Assessment of radiometric correction methods for ADS40 imagery. Photogramm. Fernerkund. Geoinform. 2012, 3, 251-266. [CrossRef] [PubMed]

33. Wald, L.; Ranchin, T.; Mangolini, M. Fusion of satellite images of different resolutions: Assessing the quality of resulting images. Photogramm. Eng. Remote Sens. 1997, 63, 691-699.

34. Aiazzi, B.; Alparone, L.; Baronti, S. Context driven fusion of high spatial and spectral resolution images based on oversampled multiresolution analysis. IEEE Trans. Geosci. Remote Sens. 2002, 40, 2300-2312. [CrossRef]

35. Cakir, L.H.; Khorram, S. Pixel Level Fusion of Panchromatic and Multispectral Images Based on Correspondence Analysis. Photogramm. Eng. Remote Sens. 2008, 74, 183-192. [CrossRef] 
36. Näsi, R.; Viljanen, N.; Oliveira, R.; Kaivosoja, J.; Niemeläinen, O.; Hakala, T.; Honkavaara, E. Optimizing radiometric processing and feature extraction of drone based hyperspectral frame format imagery for estimation of yield quantity and quality of a grass sward. Int. Arch. Photogramm. Remote Sens. Spat. Inf. Sci. 2018, 42, 1305-1310. [CrossRef]

37. Hasan, S.; Jansa, J.; Pfeifer, N. BRDF-based correction of colorized aerial LiDAR point clouds. In Proceedings of the 2015 Joint Urban Remote Sensing Event (JURSE), Lausanne, Switzerland, 30 March-1 April 2015; IEEE: Piscataway, NJ, USA, 2015.

(C) 2018 by the authors. Licensee MDPI, Basel, Switzerland. This article is an open access article distributed under the terms and conditions of the Creative Commons Attribution (CC BY) license (http:/ / creativecommons.org/licenses/by/4.0/). 